\title{
Contradictions and barriers to sustainable development of territories
}

\author{
Vladimir Kurdyukov ${ }^{1}$ and Sergey Kanurny ${ }^{1 *}$ \\ ${ }^{1}$ Don State Technical University, sq. Gagarina, 1, Rostov-on-Don, 344010, Russia
}

\begin{abstract}
The aim of the study is to identify contradictions and obstacles to the transition to sustainable development in the territories. The methodological framework is analysis and synthesis, the concept of sustainable development, institutional analysis approaches, limited rationality and opportunism in behaviour, ideas about stakeholders, and systematic and scenario-based approaches. The Sustainable Development Goals reflect interests of the world's population. However, the search for consensus on a strategy to achieve them is hampered by existing and emerging contradictions. The paper describes the practice of formulating a compromise on the environmental situation in the territory. The analysis of factors is presented in the context of theoretical constraints, interests of various territories and social groups. Gaps and various contradictions have been identified in the implementation of sustainable development concept in the territories. The contradictions between components of sustainable development; the essence of sustainable development tools; the competitiveness of the territory's products and aneffective system of internalization of externalities; various stakeholders are considered. The territories' transition to sustainable development requires the removal of considered and potential contradictions. Possible directions for this are presented.
\end{abstract}

\section{Introduction}

The Sustainable Development Goals (SDGs) agreed by heads of government in 2015 represent a major multilateral effort to change the world towards more sustainable development paths, including the needs of developing countries [1]. Acceleration is necessary to achieve goals and targets for education, sustainability of cities and communities and, in particular, climate change [2].

Analysis of the sustainable development concept in the context of modern productive forces and production relations, as well as their contradictions over natural boundaries, raises a lot of questions. The environmental friendliness of the economy is influenced by excess food production, use of agrochemicals, increase in global average temperature due to greenhouse gas emissions, and inequality in income distribution. New concepts offer a new view of productive forces and production relations, which must now be focused on the

\footnotetext{
*Corresponding author: sergay.1995@mail.ru
} 
dynamics of production that meet the basic needs of an individual rather than the needs of a market [3].

The authors [4] developed a conceptual model called 'Sustainable Development with an Axiological Perspective', which covered three dimensions: meeting human needs, natural resources and decision-making perspectives (axiologically). It implies that sustainable development can be seen as development aimed at improving the well-being of society as a whole (including future generations) in decision-making processes from an axiological point of view, given the limited resources of the environment.

Many sources propose a transition to sustainable development through the Circular Economy (CE) mechanism, which is promoted by the European Union, some countries and numerous enterprises around the world. However, the research content of the CE concept is superficial and disorganized. It is a collection of separate vague ideas from several fields and semi-scientific concepts. It is therefore important to critically examine the concept from the perspective of environmental sustainability [5]. In this case, the quantification of product and service closures (or their contribution to the $\mathrm{CE}$ ) is crucial in the development of policies and business strategies, as well as in the prioritization of evidence-based sustainable solutions. However, none of the indicators fully addresses the concept, and may lead to an undesirable shift in commitments from reducing material consumption to increasing environmental, economic or social impacts. In addition, new metrics underestimate the complexity of multiple cycles and the impact of material recycling. Cyclical indicators for sustainable decision-making should be comprehensive enough to avoid shifting commitments [6].

Current research and practice remains at an early stage, pointing to ethical, social and environmental contradictions, as well as political reservations that deserve further research [7]. There is a need to initiate local sustainability research, identifying both disagreements over local priorities, competing interests among different stakeholder groups, and risks associated with future uncertainty. Interdisciplinary research based on effective integration of computational approaches with active participation of stakeholders to mitigate impacts would be optimal [8]. Rethinking the agenda while harmonizing sustainable development and digitalization policies seems appropriate to ensure holistic sustainability.

For example, studies in two Swedish cities, Gothenburg and Helsingborg, on a compact urban planning model have shown that the model is justified by its ability to contribute to the economy, environmental and social sustainability goals. However, economic objectives prevail over environmental and social ones, despite the assertion that the three dimensions of sustainability are equally important at discursive level. Nevertheless, new measures are being designed and implemented to enhance their impact on urban planning and development practices in order to achieve balance between the three sustainability objectives [9]. An important issue, however, is that the simultaneous removal of all constraints may be challenging due to trade-offs that may arise between recommended actions. Therefore, an important task is to develop methods of resolving such trade-offs [10].

The agro-industrial sector is highly susceptible to change from unsustainable use by machinery and humans. Economic and mathematical modelling of technical re-equipment of the machinery and tractor park with simultaneous selection of an optimal operation plan in the economy [11] may reduce the level of such impact. For example, increased adoption of information and communication technologies through increased productivity and resource efficiency, reducing management costs and improving coordination in the food chain can lead to increased resilience in agriculture [12]. In order to determine their suitability and efficiency, an intellectual information system can use, for example, an 
algorithm that includes setting quality criteria, has expert feedback to correct information, allows you to choose an optimal number of function terms [13]. But, of course, it's hardly possible to talk about any processes without considering innovation. The use of new technologies and openness to innovation can be crucial in achieving sustainable development. Innovation can be a link that will help to overcome crises of various kinds and provide opportunities for identifying, analysing and testing new products and processes [14].

The biosphere and modern civilization are in the midst of instability and an impending ecological catastrophe. Human survival requires development of mechanisms, tools and policy frameworks for the transition to a new long-term sustainable social development system (both global and territorial), which will take into account interests of all social groups and stakeholders. The concept of sustainable development, which has been actively developed and promoted in recent decades, is an important part of addressing these issues. At the same time, the existing theoretical framework for sustainable development may present both threats and additional opportunities for a specific territory and its population. We will analyse threats and possibilities of implementing this concept in the context of local territories' interests.

\section{Methods}

In practice, the environmental situation in any territory is the result of a compromise between local community (often the population is partially informed, or is completely unaware of the true ecological state of the habitat), managers and owners of enterprises (who usually also act as employers), representatives of state and municipal authorities. Community members as consumers of the products of certain enterprises are indirectly involved in environmental pollution, with a negative impact on their own health. State authorities in this process act as arbiter and, depending on the degree of «environmental tension» in society, as well as social pressure from various population groups and producers, establish standards and regulations that support the state of ecosystems. At the same time, quality indicators are usually various kinds of bio-indicators that mostly demonstrate the level of social agreement, not the threshold of biosphere stability. The mentioned agreement is reached between producers, i.e. emitters of pollutants, and formal authority, which should represent the local community interests.

By subjecting large areas to influence, human beings most significantly destroy their own ecological niche, as evidenced by the increasing cases of genetic, mental and congenital disorders. The underlying mechanisms leading to the disintegration of the human genome are invisible and undetectable, and therefore require special attention from professionals concerned with preservation of public health and human population as a whole. Due to the complexity of understanding and presenting the processes of the relationship between human beings and natural environment, environmental priorities are not always in the foreground in public policy.

Present day realities show that the sustainability of the biosphere as a system has been shattered by an emerging human-transformed subsystem in which evolution has been replaced by the so-called growth-enhancing progress. Ultimately, the unidirectional developing subsystem becomes fundamentally unstable and its rate of growth is threatening.

A more progressive type of relationship should be seen as a way of removing the contradictions of the preceding form and resolving them. The transition to a new system implies overcoming the contradictions of the previous one. In order for sustainable development to become a basis for economic and social development, it is necessary to 
remove its main contradictions and barriers of transition to it and to ensure that the strategy of transition to sustainable development does not conflict with the existing system. In connection with the growing competitive confrontation between states, social groups, patterns of conduct, and capital in the context of a systemic crisis, it is necessary to identify and analyse the contradictions that impede transition to sustainable territorial development. The methodological framework of the research is analysis and synthesis, the concept of sustainable development, institutional analysis approaches, limited rationality and opportunism in behaviour, ideas about stakeholders, systematic and scenario-based approaches, logical operations with concepts. The chosen goal and focus of the research related to ensuring sustainability in the territories will allow identification of various groups of stakeholders and obstacles to sustainable development transition.

\section{Results}

Existing gaps and shortcomings in the concept of sustainable development impede the transition of territories to sustainable development. In addition, such a transition is hindered by various contradictions. Analysis of the sustainable development concept from the standpoint of contradictions between theory and practice revealed the following main points:

- Conflict between economic, environmental and social components of sustainable development.

The development of progressive ideas and their introduction into practice implies a comprehensive analysis, excluding the possibility of a free-rider. Sustainable development ideas should unite society rather than create additional risks and tools to exploit social and economic potential for environmental purposes.

Strategies for the transition to sustainable development at the international and national levels have been accepted by most states of the world. However, difficulties have arisen in establishing and harmonizing approaches in the design of implementation mechanisms. They stem from the contradictions between interests of the so-called developed Western countries, which demand a reduction in the technological burden on the natural environment on a global scale, and those of the economies of states with a heavy dependence on industry, against unilateral reduction of such loads.

Prioritizing the environmental sphere activity (as well as economic and social ones) over others can contribute to increasing social and economic stratification, social tension and economic problems, which, in turn, over time may threaten the environment as a whole, undermine the sustainability of modern civilization. It is the risks associated with the risk of technology degradation following a ban on economic activity that justify balancing all areas (i.e. the economic and social costs of closure). In addition, after the implementation of such a "de-industrialization strategy", there is an increased risk of expansion of the "green» territories by other states and various social groups. That is, it is necessary to formulate a strategy for the territory's development that includes all aspects of life and takes into account the interests of various social groups.

The situations of lack of balance between all the components of sustainable development, the development of the two pillars through the third are presented in the figure 1.

Failure to meet conditions and dependencies of the territory's social and economic sustainability [15] implies establishment of appropriate mechanisms for the redistribution of benefits and resources. For a territory, such a development would reduce the efficiency of its socio-economic system and the standard of living of part of the population, such as middle class. If green growth lags behind economic growth in the territory, additional environmental exploitation will lead to reduced environmental sustainability. If economic growth fails to 
keep pace with population growth (not to mention other factors), the standard of living falls. In this context, a key challenge for social, economic and environmental sustainability is to establish an equitable system of redistribution of benefits and resources.

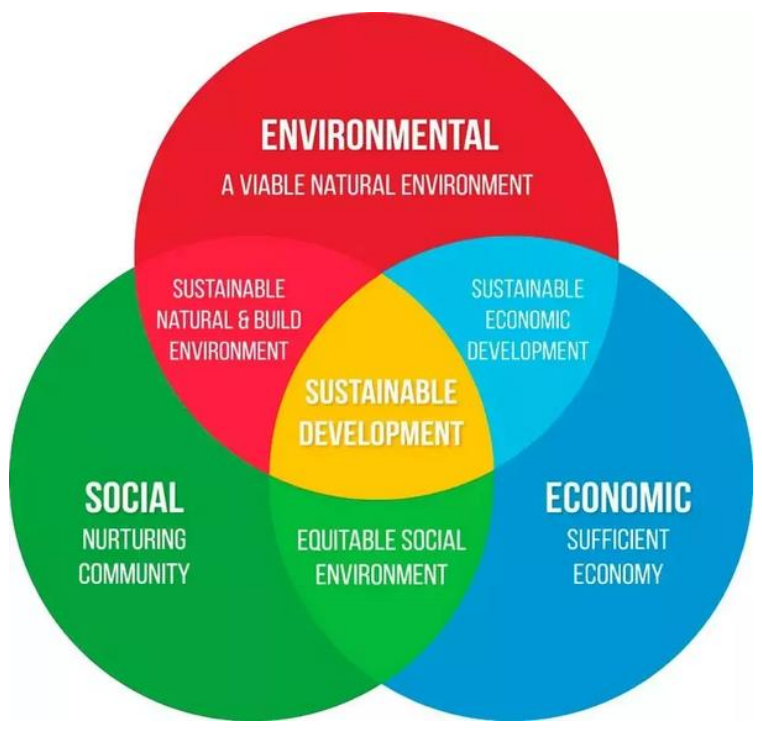

Fig. 1. Sustainability Priorities,Source:https://www.ierek.com/news/index.php/2019/07/28/ urbanplanning-and-sustainable-architectural-development/

- Different essences of sustainable development tools act as a contradiction.

The promoted sustainable development strategy can be a tool for environmental and resource conservation. But beyond that, various social groups can use the concept of sustainable development as:

- Management tool;

- Tool for changing governance and regulation structure at the global level;

- Possibility to change the structure of expenditure, assign budgetary and extrabudgetary funds (the direction of expenditure with a complex system of regulation and control);

- The opportunity to influence the formation of «rules of the game» in society, refusal to fulfil obligations;

- The tool of access to resources to the detriment of local territories (local population and environmental quality);

- A tool for greening economy in the territory.

Taking into account possible risks and interests in the competition of unscrupulous economic actors will make it possible to choose the most effective tools for the population of the territory.

- Contradiction «tool - goal» of sustainable development.

There are risks associated with the activity of various stakeholders promoting a dangerous transition strategy to sustainable development. At the same time, reducing the load on the environment and balancing all aspects of vital activity are indispensable for the long-term development of the territory.

The concept of sustainable development can be a tool to justify unfair competition and behaviour, restrict the rights of territory, social groups and states; to form new governance 
structures at the global level (e.g., UN restructuring) for growth and empowerment. In the hands of others, it can be the basis for seeking consensus among all social groups.

The transition to sustainable development at the global level is possible in two ways:

1. Reducing consumption

2. Technology development

The first can be achieved through:

- Redistribution of wealth (values, goods and resources);

- Changing consumption patterns (reduction of specific consumption of resources), changing culture;

- Population reduction.

The implementation of the second track is possible, as mentioned by Vernadsky, under the influence of scientific thought and collective work (i.e. bringing all stakeholders together to achieve a common goal).

Both, however, are flawed and run counter to the interests of national states and various interest groups that are engaged in global and regional competition. Some contradictions may be resolved regionally, within one state. Moreover, population growth and technological development threaten the governability of the social system. In this respect, the implementation of a sustainable development strategy can be used in cases of unfair competition and behaviour.

- Competitiveness of products of the territory and an effective system of internalization of externalities.

The competitiveness of the territory's products may be in short-term conflict with an effective system of internalization of externalities. The process of establishing such a system can lead to a loss of markets and a decline in investment attractiveness. At the same time, the absence of an adequate system of internalization of externalities in the long run will be counterproductive, given the emergence of green protectionism institutions. This is due, inter alia, to the main shortcomings of the economic mechanism for the use and protection of the environment and the limited use of resource and energy saving technologies. Depending on the territorial development objectives and the suitability for exploitation of the components of sustainable development, a system of internalization of externalities is formed [16] taking into account conditions for its effective functioning [17]. Inaccuracies and errors in the assessment of environmental performance hamper the optimal allocation of investment costs for the transition to environmentally sustainable development through economic efficiency measures. The lack of effective incentives to reduce man-made impacts on ecosystems makes it impossible to provide objective conditions for improving environmental quality.

- Controversy between stakeholders.

In practice, a territorial development strategy that incorporates, to varying degrees, the directions to be given to the territory and the measures required to implement them is carried out in a context of competitive confrontation between main stakeholders. The result is that the interests of the most influential social groups are taken into account.

Achievement of the goals declared by the concept of sustainable development at the territorial level is hindered, inter alia, by the crisis phenomena in the world economy. The solution of declared economic problems within states in the context of the ongoing crisis exacerbates contradictions between social groups, organizations and states. Further we will consider the relationship between various stakeholders in the territory's transition to sustainable development.

- Contradiction between the subjects of the territory.

Taking into account the ideas expressed in the work of Veblen «Teoriyaprazdnogoklassa/Theory idle class», and the basic directions of transition to 
sustainable development, the following subjects can be distinguished for the territory: the main population, technocrats and idle class.

Technological development frees the population up and reduces the dominance of monopolies and existing industries. Rapid technological development contributes to the emergence of a modernization trap, the problem of «extra» people. These circumstances provoke social tension and conflicts. At the same time, internal contradictions of scientific and technological progress are related to the need for a certain level of consumption and return on investment.

When a certain standard of living is reached in the territory, the quality of the environment becomes more important to the population. However, in times of economic change and crisis, the ability and willingness to pay can fluctuate considerably. Here, among other factors, including the manipulation of public opinion, a fair distribution of the burden in the transition to sustainable development of the territory is essential.

- Contradictions between the capitalist core and the periphery.

The discourse on transition to sustainable development often ignores information that the share of resource consumption of a small group far exceeds that of the rest of the population. In other words, the western level of consumption and the drive towards it in developing countries (albeit with some limitation) are more important for reducing the sustainability of the social system than population growth. Most of the consumption is in Europe and North America, with China, India and South-East Asia as the main manufacturing sites. If population growth is to be tackled, it should be done mainly in Asia. But that will not solve the problems of global environment. If consumption is limited, European and North American states will be subject to main regulation. But such events will not lead to tangible success in stabilizing the number of people on the planet.

The level of economic development in the territories determines the priority of various tasks. In the periphery countries, the objective of raising living standards is determined by economic model of development and need to reduce social tension. In the countries of the capitalist nucleus, the old economic model has run its course and the redistribution of wealth and resources, both within the core and periphery, is carried out through various mechanisms. Differences in opportunities, patterns and constraints of development dictate contradictions between the capitalist core and the periphery over the directions of transition to sustainable development.

- Contradiction between global and regional sustainability.

The experience of western countries shows that different methods may be suitable to a greater or lesser extent for the realization of sustainable development in a given territory. However, owing to the complexity of the territory's sustainable development objective, in the short term, the economic and social conditions of territorial sustainability may contradict the environmental objectives of a higher-level system. As a result, the following tasks need to be accomplished in order to take adequate decisions at the territorial level:

1. To set priorities and boundaries for the problems stated in the concept of sustainable development for current and future inhabitants of the territory;

2. Determine whether it is possible and appropriate to consider the implementation of sustainable development in isolation from the already established institutional framework for decision-making;

3. Identify methods that can be used to move towards sustainable development of the territory without undermining the conditions for its social, economic and environmental security.

Regional and global development is exacerbated by the confrontations of actors with the highest potential: dominant global groups, regional social groups, local populations. The 
conflict can be resolved by a technological leap, taking into account the interests of all stakeholders. Lack of complexity in addressing this issue will increase social tension.

The competition between financial and industrial capitals for a role in the emerging economic system may hamper the sustainability of territories. The credit and financial system can help and facilitate the transition to sustainable development in territories, for example, through investment and innovation loans, green investment, etc. However, credit and financial systems can both hinder the solution of local problems and push problems to other territories, that is, to transfer debts (of states, individuals, corporations) to other territories, social groups, economic agents, generations, directly or indirectly affecting the unjust redistribution of resources and benefits, which contradicts the essence of the concept of sustainable development.

Mass consumption is a major element of the modern economy and an obstacle to the transition to sustainable development. The basis for mass consumption is the credit and financial system, which stimulates demand and thus consumption. With the reduction of transaction costs, in particular through the development of information technologies, the role of the credit and financial system in the distribution of benefits and resources will diminish.

\section{Conclusion}

The Sustainable Development Goals reflect the interests of the world's population. However, the search for consensus on a strategy to achieve them is hampered by existing and emerging contradictions. Sustainability slogans can hide elements of bad conduct and competition. Various social groups and territories are threatened by such a strategy. In this regard, it is necessary to develop theoretical knowledge based on objective environmental limitations and specific features of the territory and the methodology of environmental protection, taking into account the specificities of the territory and the population interests.

The paper describes the practice of formulating a compromise on the environmental situation in the territory. The analysis of factors and origins of the theory is presented in the context of theoretical constraints, interests of various territories and social groups. The analysis of some trends in the development of modern civilization is carried out, gaps are identified, and various contradictions in the implementation of the Sustainable Development concept, which complicate the transition to sustainable development in the territories, are identified. The link between sustainability of territorial development and the behaviour models of stakeholders is considered, as are the obstacles to effective management decisions and the need to take into account the interests of various social groups.

In order for the territories to move towards sustainable development, the contradictions discussed must be resolved. To this end, it is necessary to develop and improve approaches for identifying and accommodating interests of various stakeholders. Methodological constraints and gaps in the transition to sustainable territorial development will be addressed in further studies.

The resolution of many contradictions can be achieved by convergence of methodology and principles of domestic and foreign policy in the behaviour with stakeholders. When considering alternatives, consideration of total costs and benefits will bring the creation of conditions for resolving conflicts between different stakeholders closer. 


\section{References}

1. R. Goyannes, G. Caiado, W.L. Filho, O.L. Gonçalves Quelhas, D.L. de Mattos Nascimento, L.V. Ávila, Journal of Cleaner Production 198, 1276-1288 (2018), doi.org/10.1016/j.jclepro.2018.07.102

2. G. Halkos, E-Ch. Gkampoura, Economic Analysis and Policy 70, 94-122 (2021), doi.org/10.1016/j.eap.2021.02.001

3. Ch. Nogueira, Environmental Development 30, 129-135 (2019), doi.org/10.1016/j.envdev.2019.04.004

4. I. Bolis, S.N. Morioka, L.I. Sznelwar, Journal of Cleaner Production, 83, 7-20 (2014), doi.org/10.1016/j.jclepro.2014.06.041

5. J. Korhonen, A. Honkasalo, J. Seppälä, Ecological Economics 143, 37-46 (2018), doi.org/10.1016/j.ecolecon.2017.06.041

6. B. Corona, L. Shen, D. Reike, J.R. Carreón, E. Worrell, Resources, Conservation and Recycling 151, 104498 (2019), doi.org/10.1016/j.resconrec.2019.104498

7. G. Del Río Castro, M.C. González Fernández, Á. Uruburu Colsa, Journal of Cleaner Production 280(1), 122204 (2021), doi.org/10.1016/j.jclepro.2020.122204

8. E.A. Moallemi, S. Malekpour, M. Hadjikakou, R. Raven, K. Szetey, D. Ningrum, A. Dhiaulhaq, B.A. Bryan, One Earth 3(3), 300-313 (2020), doi.org/10.1016/j.oneear.2020.08.006

9. S.E. Bibri, J. Krogstie, M. Kärrholm, Developments in the Built Environment 4, 100021 (2020), doi.org/10.1016/j.dibe.2020.100021

10. A. Sharifi, A. Dawodu, A. Cheshmehzangi, Sustainable Cities and Society 67, 102739 (67), doi.org/10.1016/j.scs.2021.102739

11. A. Alukhanyan, O. Panfilova, E3S Web of Conferences, 175, 13007 (2020), doi.org 10.1051/e3sconf/202017513007

12. N. Serbulova, et al., IOP Conf. Ser.: Earth Environ. Sci. 403, 012127 (2019), doi.org/10.1088/1755-1315/403/1/012127

13. V. Dimitrov, L. Borisova, I. Nurutdinova, E3S Web of Conferences, 175, 05027 (2020), doi.org10.1051/e3sconf/202017505027

14. N. Serbulova, et al., E3S Web of Conferences, 210, 02005 (2020), doi.org/10.1051/e3sconf/202021002005

15. V. Kurdyukov, L. Badalyan, V. Bakhtinova, A. Ovcharenko, Advances in Engineering Research, 191, 149-153 (2019) https://doi.org/10.2991/aer.k.200202.031

16. V.N. Kurdyukov, L.Kh. Badalyan, I.V. Avlasenko, L.M. Avlasenko, S.V. Kanurny, IOP Conf. Series: Earth and Environmental Science, 403(1), 012080 (2019), doi:10.1088/1755-1315/403/1/012080

17. V. Kurdyukov, S. Kanurny, E3S Web of Conferences, 210, 13005 (2020), doi.org/10.1051/e3sconf/202021013005 